what we see in our experiments, we shall probably get a hint and arrive at results which may be of importance. It is difficult to say that any discovery which is made is devoid of commercial value. Our experience in the War showed us that the most recondite phenomena, known only to a few, could be applied for the service of the country.

I have heard the fear expressed that the multiplication of laboratories may lead to something like overproduction-that there may not be enough discoveries to go round. Such a fear seems ludicrous to a physicist who knows that a discovery is not a terminus but an avenue opening up new and wider fields for work. We are surrounded on all sides by physical and chemical phenomena of which our knowledge is not even in its infancy, scarcely in embryo. Consider for example the chemical and physical properties of living matter. A tiny seed is put into the ground and becomes with nothing but the soil, water, air, and light a workshop weaving for leaf, flower, and fruit fabrics of exquisite texture, moulding these with unerring accuracy into shapes of the greatest variety and complexity, dyeing them all the colours of rainbow, often spreading the colours in patterns full of minute and elaborate detail, laying up stores of substances, most of which are beyond the power of the chemist to produce, and finally producing other seeds able to produce the same effects. Compared with results like this our workshops, our looms, our dye-works seem clumsy and inefficient. What is the mechanism by which these wonderful results are produced? We have no idea.

To find out the mechanism of this tiny seed we shall have to develop methods of investigating the changes that go on, almost molecule by molecule. Of late years methods have been devised which are continually diminishing the distance between us and the solution of these problems, and in the not too indefinite future we may hope to get to know something of the way in which those marvels are accomplished. This requires the co-operation of many sciences, and it seems to me that the new buildings at Bangor are admirably fitted to take part in this great work.

\title{
Richard of Wallingford and his Rectangulus.
}

\section{By Dr. R. T. Gunther.}

THE celebration of the sixth centenary of the elevation of Richard of Wallingford to the Abbacy. of St. Albans in ${ }^{2} 3^{26}$ is an occasion of far more than local interest, for it is also the celebration of the sixth centenary of the beginning of trigonometry in England.

Richard's father was a blacksmith in the village of Wallingford, who died when the son was only ten years of age, but Richard was fortunate enough to be adopted by the Prior of Wallingford, who sent him to Oxford at the age of seventeen. Six years later he was admitted to the monastery of St. Albans, perhaps, as Sir Edgar Wigram has suggested, because he instinctively recognised that in those days a monastery was the only refuge where a man of science could find license and leisure to prosecute his studies undisturbed. But after three years training, Abbot Hugh sent him back to Oxford as one of the students whom every Benedictine house was bound by statute to maintain at the University, in order to ensure that its learning should be kept up to standard. Apparently to the deep concern of the chronicler, Richard then proceeded to spend valuable time on mathematics and astronomy, which he was expected to devote to theology. But in 1326 he had his reward by being elected Abbot of St. Albans, and, as after events proved, turned his scientific training to good purpose by reducing the debt and by rebuilding the Cloister of his Abbey.

We have two miniature portraits of Richard of Wallingford in the illuminated chronicle of Matthew Paris. In the first he is engaged at his bench making or measuring a circular instrument with a pair of compasses. His simple tools are lying by his side and his Abbot's mitre is on the floor. In the second portrait he is pointing to the famous clock which he made for the Abbey. A point of singular interest is the fact that in both portraits he is represented with a spotty. face, indicating the ravages of the incurable disease of leprosy which he had contracted at Avignon. Indeed, of this we have confirmatory evidence in a prayer composed by him in later life after his promotion as Abbot. The words are worth quoting, if only as an example of the devotions of an English man of science of the fourteenth century.

Though I be a man of lowly state, and smitten by Thy providence with an evil plague, so that I am not worthy to walk among men, but should by law be cast without the camp; yet Thou, O Lord my God, by what secret judgement I know not, dost yet hold me in honour, such honour as I have known none of my parents or kindred to attain to, in all health of body; and as I oft-times remember with wonder at Thy great bounty, dost so incline the hearts of the great towards me, that ever when present, they $d$ not abhor my speech and the deformity of my face and hands, but rejoice to converse with me. . .

We may, therefore, claim that the miniatures are truthful representations of "The Father of Trigonometry " in England.

Wallingford's trigonometrical methods are indicated in two works, De sinubus demonstratis and De sinubus et arcubus in circulo inveniendis, and their practical application is further described in his treatise on the Art of working with a Rectangulus.

Two scientific treatises on the 'Albion' and the Rectangulus are dated about the time of his election as Abbot. Fortunately, illustrated copies of the manuscript are still extant and they include many working drawings which reveal the construction of the instruments so clearly that a reconstruction is possible.

The "Albion' has often been stated to have been the Abbey clock for which he is famous; but the evidence of the original manuscript points to its having been an elaborate Aequatorium or Volvelle composed of a number of circular dials for showing the position of the planets : the name 'Albion,' or all-by-one, having reference to the various operations which could be performed by the one instrument. There is no mention of cogwheels, pulleys, and weights, or of any driving

NO. 2978. VOL. I I8] 
or regulating apparatus in connexion with the Albion. Doubtless it was intended to be used with his other invention, the Rectangulus, with which the relative positions of stars could be measured.

In the prefatory sentences to his treatise on this instrument, Richard tells us that he invented the Rectangulus in order to obviate the laborious and difficult use of the Armillary Sphere in determining the course and place of fixed stars and planets, and for other problems which were usually solved by the astrolabe and the torquetum. The fundamental principle of the instrument is based on the theorem of Euclid on the equality of the angles and lengths of equidistant lines between parallels.

The instrument consists of three superposed limbs or rules connected by hinges in such a manner that each limb may not only be opened out at varying angles like the blade of a pocket knife, but may also be rotated round a peg-pivot below its hinge. Above all is an alidade, or rule with perforated sight-vanes, which is so hinged to the third limb that it can be either elevated above it or be moved parallel with it. The hinges may all be clamped more or less tightly by wedges driven through slots in the pegs, like those used in astrolabes.

To complete the instrument six scales of bronze were prepared and graduated. Three of these are fixed to the sides of the three limbs; the other three are movable, being pivoted on the pegs under the limbs. The lowest scale was divided along the edges into 60 equal divisions called degrees or parts of chords, gradus seu partes cordarum, each of which might, in the case of a large instrument, be further subdivided into 60 parts, while the middle or intervening band was divided by a table of right and versed chords, corde recte et verse. This middle divided band is omitted in the five other scales. The division of the upper scale of chords, which are called right chords, are numbered from the peg to the end of the scale; the lower scale, called versed chord, is numbered from the end of the rule to the peg. The ends of the alidade and upper limbs are provided with plumb-lines.

In his second treatise on the use of the Rectangulus, Wallingford explains in ten chapters how various observations and calculations are to be made. In the first place the whole instrument must be adjusted for level by a plumb-line fixed near the surface of the base pillar. The instrument is then ready for the first exercise, "To find the right and versed chord of a given arc less than a quarter of a circle and to find any arc from a given chord." The method in his own words, as translated by Sir John Findlay, is to

let the perpendicular of the second limb hang over the first limb at the given arc, the length between the peg and the string reckoned from the peg to the end of the limb is the right chord of the arc. The distance beyond the string, reckoning from the point of the limb, gives the versed chord of the same arc. The reverse process enables an arc to be found from its chord. Note that the plumb-line hangs at right angles when it falls on equal divisions of the scales on both sides of the limb, and this is chiefly why the scales of chords are double on all the scales. The right and versed sine of an arc greater than a quarter of a circle may be easily found from what has been said, for the right sine of an arc less than a quarter of a circle is the right sine of the arc of the rest of the circle. Further, the versed sine of an arc greater than the quarter of a circle but less than a semicircle is greater than the semidiameter by the amount of the right chord of the angle by which the given arc is greater than a quarter of a circle, as is shown elsewhere.

Then follow chapters upon how "To find the meridian," "To find the altitude of a star above the horizon and its azimuth," "To find the latitude of a place by a star which does not set," "To find the latitude and longitude of a star from the equinoctial circle," "The declination of a star and its latitude in the ecliptic," "To find the true place of the sun from its aspect," "To find the true place of the moon in longitude and latitude," "The true place of fixed stars in latitude and longitude."

The treatise concludes with the sentence, "The Rectangulus was invented for the purposes which have been explained, and therefore, because what has been explained is sufficient for an apt pupil, the way is clear to everything that can be done by other instruments. Here I finish."

Wallingford died in $\mathrm{I} 335$ at the age of forty-three. It is reported that the Abbot's house where he was sleeping was struck by lightning, and, weakened as he was by his disease, he did not survive the shock. His tomb is in the Abbey Sanctuary just east of the altar rails.

\section{A Remarkable Suborder of Fishes.}

D URING the Danish Dana Expeditions of I9201922 in the North Atlantic and the Gulf of Panama, under the leadership of Prof. Johs. Schmidt, a magnificent collection of ceratioid fishes was made, which forms the subject of a monograph by $\mathrm{Mr}$. C. Tate Regan, ${ }^{1}$ Keeper of Zoology in the British Museum (Natural History), from which the accompanying illustrations have been reproduced. Prior to the Dana Expeditions, and excluding the Michael Sars collection, as yet undescribed, only about sixty examples of this amazing suborder of fishes were known, so that the Dana addition of 220 specimens representing 39 species, many

1 "The Pediculate Fishes of the Suborder Ceratioidea." By C. Tate Regan. The Danish Dana Expeditions I920-1922 in the North Atlantic and the Gulf of Panama. Oceanographical Reports edited by the Dana Committee, No. 2. (Copenhagen; Gyldendalske Boghandel. London: Wheldon and Wesley, Ltd., 1926.) r5s.

NO. 2978 , VOL. II 87 of which were new to science, was of great biological value.

The Ceratioidea form part of the order Pediculata, that group of highly specialised fishes in which the first ray (illicium) of the spinous dorsal fin is placed on the head and modified into a 'line and bait.' Their characteristic features are evidently related to their conditions of life. They are inhabitants of the deeper parts of the ocean, the majority living in mid-water, probably from 500 to 500 metres below the surface, where there is little or no light. Related to the absence of light is the structure of the 'bait,' or terminal expansion of the illicium, which is a luminous bulb; the outer skin of the bulb is generally transparent, and within is a glandular sac that opens to the exterior by a pore and has a luminous secretion; the lower, or 